\title{
Does knowledge spill over across borders and technology regimes?
}

\author{
Jaap W. B. Bos ${ }^{1} \cdot$ Bertrand Candelon $^{2} \cdot$ Claire Economidou $^{3}$
}

Published online: 13 June 2016

(C) The Author(s) 2016. This article is published with open access at Springerlink.com

\begin{abstract}
This paper investigates whether technology spills over across national borders and technology regimes. We advocate a modeling strategy where improvements in technical efficiency capture technology spillovers as industries absorb and implement the best-practice technology. Dynamic panel-based techniques are used to determine whether efficiency series move together in the long run (cointegrate) and/or move closer together over time (converge). We control for technological heterogeneity and for cross-sectional dependence in the data. For a panel of manufacturing industries in six EU countries, we find evidence of technology spillovers and convergence among industries' efficiency levels across countries and mainly across adjacent technology regimes.
\end{abstract}

Keywords Technology spillovers · Efficiency · Panel cointegration $\cdot$ Convergence $\cdot$ Manufacturing industries

JEL Classification C23 $\cdot$ L60 $\cdot$ O14

Jaap W. B. Bos

j.bos@maastrichtuniversity.nl

Bertrand Candelon

b.candelon@maastrichtuniversity.nl

Claire Economidou

economidou@unipi.gr

1 Finance Department, Maastricht University School of Business and Economics, 6200 MD Maastricht, The Netherlands

2 IPAG Business School, 184 Boulevard Saint-Germain, 75006 Paris, France

3 Department of Economics, University of Piraeus, 18534 Piraeus, Greece

\section{Introduction}

Technology is a major driving force of economic growth (Romer 1990; Rivera-Batiz and Romer 1991; Grossman and Helpman 1991). The non-rival characteristics of technology imply investments in technology do not only benefit the investors but also contribute to the knowledge base that is publicly available to them. These externalities are called technology spillovers (Romer 1990). Through technology spillovers, countries that operate below the production frontier can increase output by learning from the best practice. Countries benefit from technology flows if they have the 'appropriate' technology (Abramovitz 1986; Basu and Weil 1998) and sufficient 'absorptive capacity' (Abramovitz 1986; Cohen and Levinthal 1989).

A large literature has examined the significance of purely domestic spillovers (see Mohnen 1996, for a survey), or domestic spillovers in conjunction with foreign spillovers (Coe and Helpman 1995). ${ }^{1}$ Technology transmission, both domestic and foreign, has been found to play a significant role in promoting productivity and economic growth.

The purpose of this paper is to investigate whether technology flows across industries in the EU manufacturing sector. In particular, we would like to investigate whether

\footnotetext{
1 A number of subsequent studies has extended the seminal study of Coe and Helpman (1995) in various ways. For instance, Lichtenberg and Potterie (1998), Keller (1998), Kao et al. (1999), Coe et al. (2009), Frantzen (2000), Lichtenberg and Potterie (2001), Luintel and Khan (2004) and Falvey et al. (2004) investigate international technology spillovers at the country-level while Fagerberg and Verspagen (1999), Frantzen (2000), Scarpetta and Tressel (2002), Keller (2002), Frantzen (2002), Griffith et al. (2004), Park (2004) and Cameron et al. (2005) among others, for international intra-industry and inter-industry spillovers.
} 
industries located in homogenous and presumably integrated countries benefit from technology spillovers from industries in other countries or from technology spillovers from different technology regimes. We focus on industries in the manufacturing sector rather than countries in order to account for aggregation bias due to heterogeneity in existing technologies (Bernard and Jones 1996a, b).

The present paper contributes to the existing literature in three distinct ways. A first contribution of this paper is that we measure technology spillovers in a simple and rather 'pure' manner. We propose a flexible modeling approach in exploring technology spillovers by estimating a stochastic production frontier. The latter is the empirical analog of the theoretical production possibility frontier and enables us to measure the maximum frontier output. One important advantage of focusing on maximum (frontier) output, rather than observable output, is that deviations from maximum output reflect sluggish absorption and implementation of the best practice (frontier) technology, whereas improvements in efficiency represent productivity catch-up via technology diffusion. In contrast the vast majority of the productivity literature focuses on total factor productivity (TFP), which, as a residual, measures 'anything and everything' of output growth that is not accounted by input growth. The translog index TFP growth measure ignores the concept of technical inefficiency (by unrealistically assuming that all industries are technically efficient) and inaccurately interprets technical change as TFP growth. ${ }^{2}$ While the frontier effect indicates how far the efficient frontier itself has shifted over time due to the use of better technology and equipment, the catching up effect reflects how far the industry has moved towards the efficient frontier due to the better use of technology and equipment.

Industries in the manufacturing sector, however, are characterized by different technologies. Recent theoretical and empirical contributions (Basu and Weil 1998; Acemoglu and Zilibotti 2001; Bos et al. 2010b, a) have stressed the 'appropriateness' of technology as countries (industries) choose the best technology available to them, given their input mix. Industries are members of the same technology regime (club) if their input/output combinations can be described by the same production technology (Jones 2005). Not accounting for different technologies and

\footnotetext{
${ }^{2}$ Empirical studies on technology spillovers usually test for convergence in total factor productivity (TFP) as a proxy of the technology level. TFP is evaluated as a growth accounting (Solow-) residual, usually under rather limiting assumptions about the behavior of economic units (optimizing behavior with no room for inefficiency). As a result, the observed output is assumed to be the maximum (frontier) output, in all TFP analyses. In reality, however, economic units may well differ in the efficiency with which they use the best practice (frontier) technology.
}

estimating a single stochastic frontier function can result in biased estimates of the 'true' underlying technology. Furthermore, omitted technological differences may be erroneously labeled as inefficiency (Orea and Kumbhakar 2004). Allowing for different production frontiers to account for heterogeneity in technologies in the manufacturing sector has been largely ignored by the studies that have performed frontier analyses for studying technology spillovers and catch-up (see, for instance, Semenick Alam and Sickles 2000; Kneller and Stevens 2006). To the best of our knowledge, only a handful of studies allow for heterogenous technologies and growth experiences (Koop 2001; Bos et al. 2010a).

Our second contribution, therefore, lies in the way we account for differences in technologies. We estimate separate production frontiers for each of the four technology regimes (high tech, medium-high tech, medium-low tech and low tech) in the manufacturing sector as defined by the OECD (2005) technology classification. ${ }^{3}$ As a result, we obtain efficiency levels for industries in each of the technology regimes that reflect the distance to their appropriate technology.

While a large strand in the literature explores technology spillovers across industries (countries), only a few studies pay attention to the time series properties of these spillovers (see Coe et al. 2009, for a survey). A number of studies derive their spillover estimates from (OLS) regressions, which, with non-stationary data, result in super-consistent (Stock 1987) but imprecise coefficient estimates with standard errors ill-suited for statistical inference (Kao and Chiang 2000). Ignoring integration and cointegration properties of the data it is not clear whether one estimates a structural long-run relationship or a spurious one. ${ }^{4}$ In this paper, we rely on cointegration and convergence to determine whether efficiency levels move together in the long-term (cointegrate), or, in fact, move

\footnotetext{
${ }^{3}$ Manufacturing industries are classified into different technology regimes according to their technology intensity. The OECD methodology uses two indicators of technology intensity reflecting, to different degrees, 'technology-produce' and 'technology-user' aspects: (1) R\&D expenditures divided by value added; (2) R\&D expenditures divided by production. The division of manufacturing industries into high-technology, medium-high technology, mediumlow technology and low technology groups is based on a ranking of the industries according to their average $R \& D$ intensity over 1991-1999 against aggregate OECD R\&D intensities. Industries classified to higher categories have a higher average intensity for both indicators than industries in lower categories.

${ }^{4}$ Few studies (see, for instance, Coe and Helpman 1995; Keller 2002) acknowledge that inference tests of their results could be are unreliable and suggest that compelling evidence of panel cointegration is needed to support their estimation strategy. An exemption are the studies of Frantzen (2000, (2002) that account for the stationary properties of the data when studying the international intra-industry and inter-industry spillovers.
} 
closer together over time (converge). For instance, increased integration and competition in the EU can lead to more efficient use of resources among industries. Thus efficiency levels may track one another over time as industries attempt to follow each other's efficiency advances in order to remain competitive. Therefore, accepting the cointegration null for a set of industries would indicate a long-run relationship in the technology transfer within the cointegrated set and potential convergence; in contrast, lack of cointegration of an industry's efficiency score with those of its counterparts may reflect the industry's inability to absorb the existing technology.

To the best of our knowledge, there have been only two studies that are close to our modeling (frontier) approach and investigate the time series properties of technical efficiency in the context of technology spillovers and convergence. Cornwell and Wächer (1999) examine whether a long-term relationship exists between country-level technical efficiencies in a sample of 26 OECD countries and whether these efficiencies converge. Semenick Alam and Sickles (2000) present a firm-level study on the role of market structure and the developments in efficiency for the US airline industry. Their results support fairly strong evidence of cointegration and convergence among EU countries (Cornwell and Wächer 1999) and existence of a long-run relationship of efficiency levels and, over time, convergence among US carriers (Semenick Alam and Sickles 2000).

Notwithstanding, both aforementioned studies as well as studies that investigate $R \& D$ trade-related technology spillovers using cointegration analysis (Frantzen $2000,2002)$ rely on cointegration techniques that do not allow for potential cross-sectional dependence. Cross-sectional dependence, which only very recently has gained some attention in the literature, appears to be, however, the case in many macroeconomic applications (e.g. convergence hypothesis tests) where time series are contemporaneously correlated due to (spatial) spillover effects, common unobserved shocks, or a combination of these factors (Pesaran 2004). If there is cross-sectional dependence, the traditional assumption of orthogonality of the individual series' error terms is violated, and cointegration test statistics are biased. Furthermore, none of the aforementioned related studies proceeds with estimating longrun cointegrating relationships, discussing the nature of potential long-term linkages. Therefore, the third contribution of this paper lies in the use of recently developed dynamic panel-based cointegration techniques to determine whether efficiency series have moved together in the longrun (cointegrate) and to estimate these long-run linkages using appropriate estimators, which take into consideration cross-sectional dependencies.
We apply the proposed methodology to a sample of 21 manufacturing industries for six European countries, over the period 1980-1997. Each industry is allocated to one of the four technology regimes, as classified by the OECD (2005): high, medium-high, medium-low and low technology. Taking annual averages for each technology regime in each country, we explore the properties of a total of $24(4 \times 6)$ series, with three sets of questions in mind: (1) are there technology spillovers across countries? (2) are there technology spillovers across technology regimes? and lastly (3) is there any evidence of convergence?

Overall, our results reveal that there is fairly strong evidence that industries' efficiency levels have moved together in the long-run (cointegrate) mainly across technology regimes and across borders. It appears that competitive forces in the EU have led, to a certain extent, to more efficient use of resources among industries as their efficiency levels have tracked one another over time in an attempt to follow each other's efficiency advances in order to remain competitive. The estimation of the long-run relationships between efficiency levels indicates that technological proximity is of the upmost importance. Finally, industries' efficiency levels have also moved closer together over time (converge) both in cross-country and cross-regime analysis. However, the extent to which convergence takes place across countries and across technology regimes differs significantly.

The remainder of the paper proceeds as follows. Section 2 considers a model of production that allows for technical inefficiency and presents the econometric methodology and specifications for estimation. Section 2.4 introduces the data. Empirical results are presented in Sect. 3. Section 4 summarizes the findings and concludes.

\section{Methodology and data}

In this section, we first discuss the concept of technical efficiency and introduce a model of production that enables us to allow for inefficiency. Next, we discuss recent developments in panel-based integration and cointegration analysis to examine whether there is a long-run structural relationship among the efficiency series across countries or across technology regimes. Lastly, we describe the convergence tests we shall use to examine whether there is convergence across across countries or technology regimes.

\subsection{Technical efficiency in a stochastic Frontier model of production}

An industry is technically efficient if an increase in its output requires an increase in at least one input. A 
technically inefficient industry can produce the same output with less of at least one input. Alternatively, it can use the same inputs to produce more of at least one output (Koopmans 1951). ${ }^{5}$

We demonstrate the concepts of technical efficiency and production frontiers with a simple one output, one input example in Fig. 1. In the graph, we consider three cases. An industry operating under the frontier of Regime 1 in (a) cannot increase output without increasing its input, whereas an industry operating under the frontier of Regime 1 in (b) can try to absorb the (superior) production skills of (a) and increase its technical efficiency. Similarly, an industry operating under the frontier of Regime 2 in (d) can increase its efficiency by absorbing the production skills of an industry operating under the frontier of Regime 2 in (c). The latter industry, however, can not increase its output without either increasing its input, or through positive technical change, i.e. an outward shift of the regime's frontier over time.

To measure efficiency, we estimate the following translog stochastic frontier production specification: ${ }^{6}$

$$
\begin{aligned}
\ln Y_{i j t}= & \beta_{i j}+\beta_{1} \ln K_{i j t}+\beta_{2} \ln L_{i j t}+\frac{1}{2} \beta_{3} \ln K_{i j t}^{2}+\frac{1}{2} \beta_{4} \ln L_{i j t}^{2} \\
& +\beta_{5} \ln K_{i j t} \ln L_{i j t}+\gamma_{t} D_{t}+\delta_{k t} \ln K_{i j t} D_{t} \\
& +\delta_{l t} \ln L_{i j t} D_{t}+v_{i j t}-u_{i j t}
\end{aligned}
$$

where $Y_{i j t}$ is the level of output in country $i$, in industry $j$, at time $t ; u_{i j t} \geq 0$ is normally distribution, truncated at $\mu,\left|N\left(\mu, \sigma_{u}^{2}\right)\right|$, and independent from the noise term, $v_{i j t} ; \beta_{i j}$ are country-industry specific fixed effects.

An industry is inefficient $\left(T E=\exp \left\{-u_{i j t}\right\}<1\right)$ if it fails to absorb the best-practice technology. In this respect, our approach is comparable to non-frontier studies (Bernard and Jones 1996a, b; Scarpetta and Tressel 2002; Griffith et al. 2004; Cameron et al. 2005) that measure impediments to this absorptive capacity using total factor productivity (TFP) changes. However, in their framework the latter can be seen as a combination of technical change (frontier shift) and efficiency change (catching up effect).

As Baltagi and Griffin (1988) have shown, Solow's general index of technical change relies on three restrictive assumptions: "constant returns to scale, neutral technical

\footnotetext{
${ }^{5}$ Industries may also be inefficient because they are unable to combine inputs and outputs in optimal proportions for given prices. In the current paper, we do not consider this 'allocative efficiency', not only because price information is scarce, but also because the positive (negative) technology spillovers that we want to measure should result in reductions (increases) of technical slack. Therefore, in this paper the term 'efficiency' refers to technical efficiency only.

${ }^{6}$ We have tested whether a translog specification is indeed preferred to a Cobb-Douglas specification. Our tests (not reported here) favor a translog specification.
}

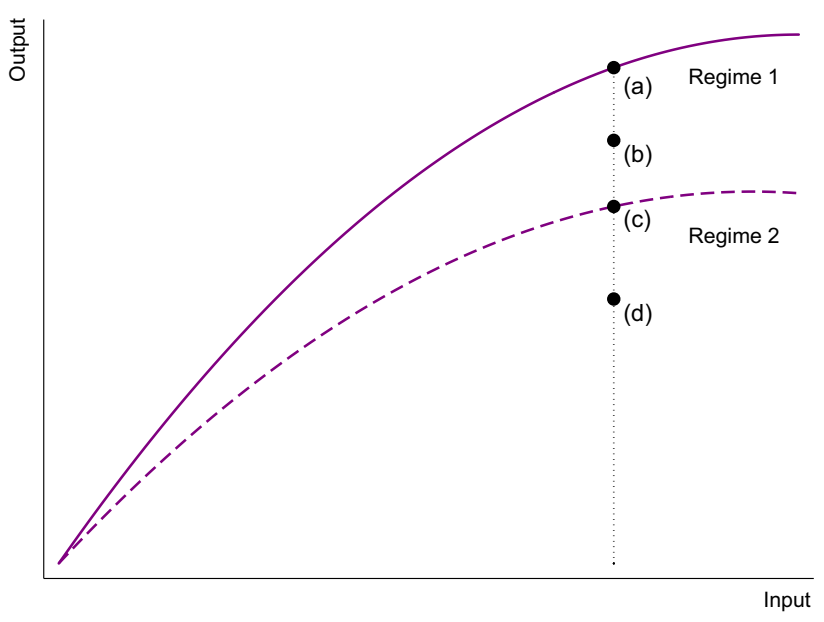

Fig. 1 Technical efficiency

change, and perfect competition in both output and factor input markets" (p. 23). ${ }^{7}$ We follow Baltagi and Griffin (1988) and include a set of time dummies $D_{t}$, whichinteracted with $K$ and $L$-allow us to measure a more general Tornqvist index of technical change as proposed by Diewert (1976).

Manufacturing industries can be grouped into four technology regimes: high, medium-high, medium-low and low regime. The division of the industries into technology regimes is based on the OECD (2005) classification. ${ }^{8}$ Accordingly, we estimate four production frontier functions, based on the specification defined in Eq. (1), one for each regime. Industries in each one of the four technology regimes are benchmarked against each group's production frontier and technical efficiencies are calculated. In our second stage analysis, we rely on cointegration and convergence tests to determine whether these efficiency levels have moved together in the long-term (cointegrate), or, in fact, move closer together over time (converge).

For our first stage frontier estimation, we want to impose as little additional constraints as possible on the distribution and behavior (over time) of efficiency. Therefore, we follow Greene (2005) and estimate a 'true' fixed effects model, in which the fixed effects are allowed to be correlated with the other parameters, but they are truly independent of the error term and inefficiency. To see why this is important, consider the case in which an industry is inefficient, but its inefficiency is constant over time. In that case, if we estimate a fixed effect model in which our fixed effects behave like standard dummy variables, this

\footnotetext{
7 See Biesebroeck (2007) for an excellent review on methodological issues on measuring total factor productivity, TFP.

8 The OECD classification of industries is based on the analysis of R\&D expenditure and output of 12 OECD countries according to ISICRev.3 and covers the period 1991-1999. On the criteria and procedure followed see OECD (2005, pp. 181-184).
} 
industry's fixed effect will absorb the inefficiency, and the industry will appear to be efficient. A second problem, in light of our analysis, that is solved by Greene's model is fact that in previous fixed effects panel formulations, inefficiency was assumed to be time invariant. ${ }^{9}$

Nevertheless, given that we shall use the efficiency scores generated by the true fixed effects model in a second stage cointegration analysis, we have to face a second set of problems. Simar and Wilson (2007) list a total of four issues we need to consider. ${ }^{10}$ First, they emphasize that since the sample used for estimating the efficient frontier does not include all possible efficient production possibilities, the estimated efficiency scores are upwardly biased (see for example Barros and Dieke 2008). Since we are interested in the dynamics of efficiency scores, rather than their level, and estimate a stochastic frontier model-as opposed to the deterministic models (Simar and Wilson 2007) refer to-we do not think this issue carries a lot of weight in light of our analysis. The same holds for the second problem Simar and Wilson (2007) address: the fact that a second-stage analysis typically includes additional covariates, that may be correlated with the covariates used in the first stage. The only covariates we shall use in our second stage are efficiency scores generated by other frontier estimations, and in so doing we include appropriate (country- and/or technology-specific) fixed effects in our second stage. Third, Simar and Wilson (2007) emphasize that a second stage estimation should take into account the fact that the efficiency scores generated in the first stage are restricted to a $[0,1]$ interval. Therefore, after estimating our stochastic frontier model outlined in Eq. (1), we shall use the untransformed scores $u_{i, t} \sim\left|N\left(\mu, \sigma_{u}^{2}\right)\right|$, rather than the transformed $\exp \left\{-u_{i j t}\right\}$, which are indeed defined on the interval $[0,1]$. In doing so, we conveniently benefit from the fact that we bootstrap in this second stage, and can therefore accommodate the non-normality of the untransformed scores with some confidence.

The final problem discussed by Simar and Wilson (2007), is the most important in light of our second stage cointegration analysis: as emphasized in their paper, since the true efficiency scores are not directly observed in the first stage, the usual assumption of independently distributed error terms is (likely to be) violated. To address this problem, we make use of recent developments in panel cointegration tests, allowing for cross-sectional dependence (Bai and Ng 2004; Palm et al. 2008). This is also the

\footnotetext{
9 A third problem solved by Greene's model is the fact that it can accommodate time invariant covariates.

10 The paper by Simar and Wilson (2007) proposes a bootstrap approach for a second stage analysis in a non-parametric Data Envelopment Analysis. However, as explained in their section 5, the problems highlighted in their paper-and reiterated here-easily translate to the case of fully parametric models as applied here.
}

main reason why we opt for a two-stage approach, rather than follow Battese and Coelli (1995), and impose a common linear trend on $v_{i j t}$. Not only could we then not test for the significance of the time trend in a pannel setting in the same manner we do now, but more importantly we risk biasing our results further by not allowing for cross-sectional dependence. Given that without the latter, it is hard to argue that there can be spillovers at all, we pursue our two stage procedure here.

We next turn to our approach regarding the panel unit root and panel cointegration analysis.

\subsection{Panel unit root and cointegration analysis}

The main goal of the paper is to identify and explain the long-run dynamics between efficiency levels of different technology regimes of the EU manufacturing industries in our sample. Increased trade and competition in the EU could lead to more efficient use of the resources among industries. In that case, efficiency levels should track one another over time as industries within each regime attempt to follow each other's efficiency advances in order to remain competitive; otherwise lack of efficiency comovement could indicate inability to capitalize on technology other industries are employing.

To examine the long-run properties of technology spillovers, captured by the efficiency series, we employ cointegration techniques. ${ }^{11}$ Cointegration examines the existence of stationary relationships between non-stationary variables and indicates that variables possess a long run common feature. A series possesses a unit root, i.e. it has a stochastic trend or is non-stationary if its statistical properties depend on time, and it is said to be integrated of order $d, I(d)$ if its d-difference does not posses a stochastic trend. If two or more series are themselves non-stationary, but a linear combination of them is stationary, then the series are said to be cointegrated. Cointegrated variables share similar stochastic patterns in the long-run and cannot move too far away from another. In contrast, lack of cointegration suggests that there is no long-term link between each other.

Panel-based cointegration techniques are particularly well-suited for the study of technology spillovers for a number of reasons. First, the focus is on the long-run relationships, which would be obscured if the equations are estimated in first differences instead of in levels of the variables. Second, the increased power of the tests comes

\footnotetext{
$\overline{11}$ Whether the use of technical efficiency (TE) in a second stage analysis is appropriate, is an issue of debate, given the fact that it is a generated regressor, which is assumed to be i.i.d. (see Tsionas and Christopoulos 2001). In this paper, we approach this debate from a purely empirical perspective, by testing for non-stationarity of efficiency using a broad range of panel unit root tests.
} 
from exploiting commonalities across industries (countries), given the limited time span. ${ }^{12}$ Third, parameter estimates are super-consistent and therefore robust to omitted variables, simultaneity and endogeneity problems. Thus, one can avoid the difficult task of finding valid instruments for some variables that would be necessary in the case of estimating a short-run relationship (Coe et al. 2009).

The implementation of the cointegration procedure entails first confirmation that the data are indeed non-stationary. Combining time-series information with crosssectional information, panel unit root tests can be more precise and powerful by reducing the error-in-rejection probability (size distortion), especially when the time-series is not very long. Consider the following $\mathrm{AR}(1)$ process for panel data:

$y_{i t}=\rho_{i} y_{i t-1}+\varepsilon_{i t}$

where $y$ represents the dependent variable, $x$ is a vector of independent variables, $\rho$ is a coefficient and $\varepsilon$ is the disturbance term.

Depending on assumptions regarding the homogeneity (heterogeneity) of correlations in the data, several tests have been developed to identify unit roots in panel data The seminal study of Levin et al. (2002) (LLC hereafter) considers a homogenous autoregressive root under the alternative hypothesis. ${ }^{13}$ More specifically, the tests proposed by LLC assume that there is a common unit-root process between cross-sections so that $\rho_{i}=\rho$ for all $i$. Im et al. (1997, (2003) relax the homogeneity assumption and propose panel unit root tests that permit heterogeneity of the autoregressive root under the alternative so that $\rho_{i}$ may vary freely between cross-sections. They present two group-mean panel unit root tests designed against the heterogenous alternatives. The two tests are executed with a t-test based on ADF regressions (IPS hereafter) and a Lagrange multiplier (LM) test. Nevertheless, these tests, labeled as "first generation" tests, do not take into account the cross-sectional dependence. To overcome this shortcoming, a "second generation" of panel unit root tests have been proposed. ${ }^{14}$ Among them, the tests developed by

\footnotetext{
12 The advantage of the panel data approach is that it enables us to determine the long-run relation among variables avoiding well-known problems that occur in using traditional time series cointegration testing (i.e., lower power of statistics due to small sample sizes). By allowing data to be pooled in the cross-sectional dimension, panelbased integration and cointegration techniques reduce small sample limitations. The use of the time-series dimension captures the longrun information contained in the data, and at the same time captures the heterogeneity in the short-run dynamics among different industries.

13 This study is based on the earlier works of Levin and Lin (1992, 1993).

${ }^{14}$ See Gengenbach et al. (2010) for a survey.
}

Palm et al. (2008) and Bai and $\mathrm{Ng}$ (2004) are particularly designed for finite samples. Palm et al. (2008) propose a bootstrap version of the LLC and IPS tests while Bai and $\mathrm{Ng}$ (2004) suggest a modified version of the panel unit root test of Maddala and Wu (1999) but on the idiosyncratic component, i.e. once common component has been removed. We examine the stationarity of our efficiency series based on these two tests.

Having established the presence of a unit root in all series of interest, the next step consists of testing for cointegration among efficiency levels. Like panel unit root tests, panel cointegration tests have been motivated by the search for more powerful tests than those obtained by applying individual time series cointegration tests, which have lower power, especially when the time dimension is rather small.

Most panel cointegration tests are built from the residuals previously obtained by the panel regression model:

$y_{i t}=x_{i t}^{\prime} \beta+\varepsilon_{i t}$

where $y_{i t}$ and $x_{i t}$ are I(1). Several tests have been proposed, such as Dickey-Fuller (DF) and Augmented Dickey Fuller (ADF)-type unit root tests for $\varepsilon_{i t}$ as a test for the null of cointegration (or no cointegration).

The statistical properties of such tests are derived under the assumption of cross-sectional independence, which greatly simplifies the derivation of limiting distributions of the panel test statistics. Cross-sectional independence is not however a tenable assumption when countries (industries) are hit by the same shocks such as oil price shocks, technological revolutions, exchange rate shocks, monetary shocks and so forth. ${ }^{15}$ For our six EU countries it is very difficult to assume that technology developments are entirely independent. Violation of the independence assumption leads to test statistics that are biased favoring the existence of cointegration and to coefficient estimates that are not super consistent.

For this purpose, a number of ('second generation') tests have been proposed (Phillips and Sul 2003; Groen and Kleinbergen 2003) to allow for cross-sectional dependence. We test for the null hypothesis of no cointegration following a methodology proposed in the recent work of Fachin (2007). This study introduces block-bootstrapped versions of the well known panel cointegration test of

\footnotetext{
15 The plausibility of cross-sectional independence has been questioned in the literature as time series are found to be contemporaneously correlated (Pesaran 2004). Cross-sectional dependence can arise, in general, due to omitted observed common factors, (spatial) spillover effects, unobserved common factors, or general residual interdependence that could remain even when all the observed and unobserved common factors are taken into account. In the presence of cross-sectional dependence as well as when the cross sectional dimension is small with respect to the time dimension, conventional (first generation) cointegration tests are shown to be biased.
} 
Pedroni (1999). Fachin proposes two bootstrapped tests $(F D B 1, F D B 2)$ that both rely on the fast distribution bootstrapping procedures suggested by Davidson and MacKinnon (2000). ${ }^{16}$ Both procedures incorporate the standard assumptions for efficient maximum likelihood estimators, but generate statistics that have limit properties that are less affected by sample size than standard bootstrapping procedures. $F D B 1$ differs from $F D B 2$ in that the former has, in theory, slightly better limit properties, whereas the latter is somewhat less computationally demanding. As Davidson and MacKinnon (2000, p. 7) point out, "it is almost costless to compute $F D B 2$ if $F D B 1$ is already being computed, it may be useful to do so as a check on the accuracy of the latter." In the original paper, Fachin (2007) shows the validity of the bootstrapped versions of the cointegration tests via Monte-Carlo simulations, but recently Palm et al. (2008) have demonstrated theoretically that the bootstrap approach behaves adequately in such a framework. The bootstrapped versions of the group- $t$ and median- $t$ statistics for the null hypothesis of no cointegration are robust to cross-sectional dependence and small sample bias. ${ }^{17}$

Lastly, one can proceed with estimating the long-run cointegrated relationship. Chen et al. (1999) have proven that the ordinary-least-squares (OLS) estimator is biased in a cointegrated panel framework and thus may lead to spurious regression. Fully-Modified OLS (FMOLS) addresses potential endogeneity of the regressors and serial correlation in order to obtain asymptotically unbiased estimates of the long run parameters. More specifically, FMOLS is a non-parametric approach that controls for possible correlation between the error term and the first differences of the regressors and removes nuisance parameters (Dreger and Reimers 2005; Pedroni 2001). ${ }^{18}$ Nevertheless, Bai et al. (2009) (BKN hereafter) prove that in presence of cross-sectional dependence generated by unobserved global stochastic trends traditional FMOLS estimator is biased. ${ }^{19}$ They thus propose an iterative procedure to extract the common factor and to estimate the model simultaneously. These common factors, whatever they may be, allow us to have an estimation robust to cross-

\footnotetext{
${ }^{16} F D B 1$ and $F D B 2$ stand for fast distribution bootstrapped tests 1 and 2 .

17 The tests based on the bootstrap method are robust to non i.i.d.ness and in particular to cross-sectional dependence, since the bootstrap procedure consists of draws from (the residual of) the empirical distribution, and not the theoretical distribution as with Monte-Carlo methods.

18 An alternative estimator suggested by Kao and Chiang (2000) is the Dynamic OLS (DOLS) estimator, which also corrects for potential endogeneity of the regressors and serial correlation. Banerjee et al. (2000) have shown that both estimators are asymptotically equivalent.

19 For related applications of FMOLS, see Fachin (2007) and Tsionas and Christopoulos (2001).
}

sectional dependence, which is not the case when implementing DOLS or FMOLS methods.

More formally, whereas FMOLS considers the following, general model:

$y_{i t}=\alpha_{i}+\beta_{i} x_{i t}+u_{i t}$

where $x_{i t}=x_{i t-1}+\varepsilon_{i t}$, and $\omega_{i t}=\left(u_{i t}, \varepsilon_{i t}\right)^{\prime}$.

BKN model the cross-section dependence by imposing a factor structure on $u_{i t}$. Therefore, the general version of their model becomes:

$y_{i t}=\alpha_{i}+\beta_{i} x_{i t}+\lambda_{i} F_{i t}+e_{i t}$

where $F_{i t}$ is a qx1 vector of latent common factors, $e_{i t}$ is a qx1 vector of factor loadings. ${ }^{20}$

We employ the BKN estimator for dynamic heterogenous panels to estimate long-run equations for cross-border and cross-regime spillovers. As normalization is performed with respect on a certain country, we estimate the following equation: ${ }^{21}$

$T E_{c r t}=\alpha_{r}+\sum_{\substack{i=1 \\ i \neq c}}^{5} T E_{i r t}^{\prime} \beta_{i}+\varepsilon_{i r t}$,

where $i$ is the country subscript $(i=1, \ldots, 5), c$ is the country on which the equation is normalized, $t$ is the time subscript $(t=, 1 \ldots, 18), \quad r$ is the regime subscript ( $r=H, M H, M L, L)$, and regime-specific fixed effects $\alpha_{r}$ are included.

Equation (6) is estimated normalizing on each of the six countries, respectively. Similarly, for cross-regime spillovers normalizing on the low technology regime, we estimate the following equation:

$T E_{i g t}=\alpha_{i}+\sum_{\substack{r=1 \\ r \neq g}}^{3} T E_{i r t}^{\prime} \beta_{r}+\varepsilon_{i r t}$

where $g$ is the technology regime on which the equation is normalized, $i$ is the country subscript $(i=1, \ldots, 6)$, country-specific fixed effects $\alpha_{i}$ are included and other subscripts are the same as for Eq. (6). Equation (7) is also estimated normalizing on each of the technology regimes, respectively.

\footnotetext{
The number of common factors $F_{i t}$ is determined individually for each panel unit root. With respect to the cointegration part, we include for a test of cross-country spillovers, a set of $5 \times 1$ common factors ( 6 minus the reference/normalizing country), and for a test of cross-regime spillovers, a set of $3 \times 1$ common factors ( 4 minus the reference/normalizing regime).

${ }^{21}$ The common factor is not reported in the coming equation for sake of clarity.
} 


\subsection{Convergence}

The presence of cointegration indicates a long-run relationship between the efficiency series. However, this does not necessarily imply convergence of efficiency levels. Tests of convergence in the economic growth literature (Baumol 1986) determine whether there is a closing of the gap between inefficient and efficient industries over time.

To investigate the convergence hypothesis, we run simple regressions of time-averaged efficiency growth rates on the initial level of efficiency:

$\Delta T E_{i j}=\beta_{0}+\beta_{1} T E_{i j, 1980}+\varepsilon_{i j}$

where $\Delta T E_{i j}$ denotes the average growth rate of the efficiency level of industry $j$ in country $i$ between 1980 and $1997, T E_{i j, 1980}$ is the initial level of efficiency in year 1980 and $\varepsilon_{i j}$ an error term.

We test for convergence across technology regimes, by estimating equation (8) for all industries in a country, controlling for technology regime-specific fixed effects. Convergence across technology regimes in all countries is tested in the same manner, but with country-technology regime-specific fixed effects. We also test for convergence within technology regimes, by estimating equation (8) for all industries in a technology regime. Again, we perform this test both for each country and for all countries jointly, and include country-specific fixed effects in the latter case.

In the tradition of Baumol (1986) and Barro (1991, (1997), a negative and statistically significant coefficient on the initial level of efficiency can be interpreted as indication of convergence of efficiency levels. The higher the initial level of efficiency is, the slower that level should grow. This phenomenon is the result of the public nature of technology that spills over from leaders to followers, as the latter group learns from the former and tries to catch-up.

\subsection{Data}

Our aim is to include as many industries as possible, since we are primarily interested in comparing industries thatpotentially_produce using different technologies. Our analysis covers 21 two-, three- and four-digit industries in manufacturing for six countries (Finland, France, Germany, Italy, Netherlands and Spain) over the period 1980-1997, where the time span is determined by the data availability for the highest level of disaggregation.

The current selection of EU countries is the largest number of countries in the Euro area-the area which is characterized by common economic policies, high competition and volume of trade-for which the data are available for a wide selection of industries and for a large time span. For instance, gross fixed capital formation (for constructing physical capital) data on the industry level are largely missing for a number of industries for Greece, Luxembourg, Portugal and Belgium. ${ }^{22}$ Overall, choosing to investigate more countries would significantly decrease the number of industries in our sample, as well as result in a higher aggregation of industries. ${ }^{23}$ Our fairly homogenous sample reduces the possibility of additional unobserved factors driving our result of economically and statistically significantly different technology regimes and potential technology spillovers.

We start our data collection at the two-digit level, using the International System of Industries Classification Code (ISIC, revision 3) classification. If data on output, capital stock and labor are available at a higher disaggregation level (three- or four-digit), we disaggregate further. Clearly, we avoid double counting by only including the latter at the highest disaggregation level. The manufacturing industries considered in our analysis and their ISIC codes are presented in the "Appendix" Table 6.

Annual raw data are retrieved from various sources. Data on industry output (value added) and investment (for constructing capital stocks) are retrieved from the OECD (2002) Structural Analysis Database (STAN). Data on labor (annual total hours worked) are extracted from the Groningen Growth and Development Centre (GGDC) (2006) 60-Industry Database. ${ }^{24}$ The same ISIC code is used for all data sources. Definitions of the variables are provided in the "Appendix".

\footnotetext{
${ }^{22}$ Our sample could also expanded to include few more countries for which the data are available namely, Denmark, Norway, Sweden, and U.K. In contrast to the Euro area countries, where all the price data for all industries were given in euros, price data for the rest of the European countries were expressed in local currency units. Tradeweighted exchange rates constructed for the aggregate economy cannot always capture the changes in industry competitive conditions associated with movements in specific bilateral exchange rates. Exchange rates constructed using information on industry-specific trade partners are better suited for this task. Unfortunately, there is no such database available for the European industries, therefore, we restrain from including these countries in the present analysis.

${ }^{23}$ Papers close to our line of research investigate fewer industries; for instance six industries (Koop 2001) over 1970-1988 or nine industries (Kneller and Stevens 2006) over 1973-1991 for a panel of OECD countries, eleven and twelve, respectively.

${ }^{24}$ The Groningen Growth and Development Centre (GGDC) (2006) 60-Industry Database provides output (value added) and labour (hours worked) data for 27 manufacturing industries. Unfortunately, there are no data for gross fixed capital formation to construct capital stock. The OECD (2002) Structural Analysis Database (STAN) contains all information needed, i.e., value added, investment and labor (number of employes) for 21 industries. Therefore, we could have relied entirely on the STAN but since we care about the productivity (efficiency and technology) of every industry, we use annual hours worked in the industry and not number of employees. Eventually, both databases, STAN and GGDC, contain similar information and are subject to the same methodologies as the later builds on the former.
} 
Table 1 Frontier results

\begin{tabular}{lcccc}
\hline & High & Medium-high & Medium-low & \multicolumn{1}{l}{ Low } \\
\hline$L L($ Obs. $)$ & $-467.428(540)$ & $111.082(432)$ & $-415.489(756)$ & $139.398(540)$ \\
$\sigma(t$ value $)$ & $1.344(23.773)$ & $0.458(31.299)$ & $1.032(33.918)$ & $0.477(38.410)$ \\
$\lambda(t$ value $)$ & $1.954(6.658)$ & $1.947(5.853)$ & $2.251(6.572)$ & $2.891(8.434)$ \\
$M R T S(\mathrm{SD})$ & $-3.820(5.194)$ & $-2.245(2.154)$ & $-1.585(3.599)$ & $-1.332(0.675)$ \\
$T E(\mathrm{SD})$ & $0.484(0.061)$ & $0.779(0.035)$ & $0.580(0.051)$ & $0.784(0.050)$ \\
\hline
\end{tabular}

$L L$ is log-likelihood; $\sigma=\left(\sigma_{u}^{2}+\sigma_{v}^{2}\right)^{1 / 2} ; \lambda=\sigma_{u} / \sigma_{v} ;$ MRTS = marginal rate of technical substitution (marginal product of labor/marginal product of capital); and $T E$ is the technical efficiency as defined in Sect. 2.1. $O b s$ stands for number of observations and $S D$ for standard deviation

\section{Results}

\subsection{Frontier results}

We estimate equation (1) for each technology regime. Table 1 contains the most important frontier results. ${ }^{25}$ Both $\sigma$ (the composite standard deviation) and $\lambda$ (the ratio of the standard deviation of efficiency over the standard deviation of the noise term) are highly significant for all technology regimes. For high-tech industries, $\lambda$ is 1.954 , and significant at the $1 \%$ level, indicating that the variance in inefficiency is about twice the size of noise in this technology regime. Much the same holds for medium-high, mediumlow and low-tech industries, where $\lambda$ is $1.947,2.251$ and 2.891 , respectively, and also always significant at the $1 \%$ level.

For industries in each technology regime, we also calculated the marginal rate of technical substitution (MRTS), as the negative of the ratio of the marginal product of labor capital. The MRTS measures the rate at which labor can be substituted for capital, keeping output constant. As expected, the MRTS gradually increases as we move from the high technology regime to the low technology regime and thereby increase capital intensity.

Compared to their own frontier, industries in the low technology regime are on average the most efficient $(78.4 \%)$. The least efficient, on average, are industries in the high technology regime $(48.4 \%)$. The spread of efficiency, however, is the highest for this regime. Figure 2 shows the efficiency distributions for each technology regime. Compared to their own frontier, industries in the medium-high and low technology regime are on average the most efficient. Also, the spread of efficiency levels is relatively low in these regimes. Medium-low technology industries are, compared to their own frontier, on average less efficient. But the spread of efficiency levels in this regime is much higher than the spread in the medium-high technology regime.

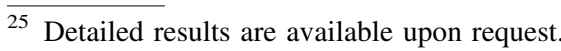

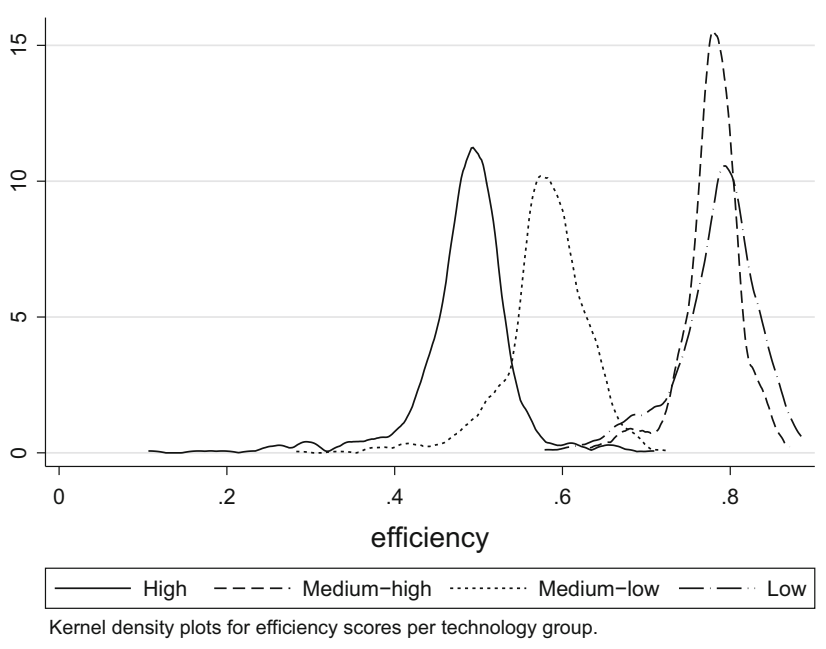

Fig. 2 Technical efficiency distribution for all technology regimes

Apparently, both the mean level and the spread of efficiency are affected by the diversity of industries in a technology regime. The latter, is particular apparent for industries in the high technology regime, which includes for example the aerospace (AER) and the medical industry (MED), and for industries in the medium-low technology regime, which includes for example the shipbuilding industry (SHI) and the other non-metallic mineral products industry (ONM). As a result, the high and medium-low regimes may have the most potential for convergence (an issue to which we return in Sect. 3.3). Some evidence of the latter can already be gathered by simply considering the development of efficiency within each regime over time. As an example, consider Fig. 3, which shows that over time average efficiency increased and its standard deviation decreased for industries in the high-tech regime.

Table 2 contains average efficiency levels as well as average growth rates of efficiency over the sample period for each industry in each technology regime in each country. On the whole, Table 2 reveals few straightforward patterns. The fast growing industries in the medium-high, medium-low and low technology regimes are located in the Netherlands (Motor vehicles (MOT), petroleum products 


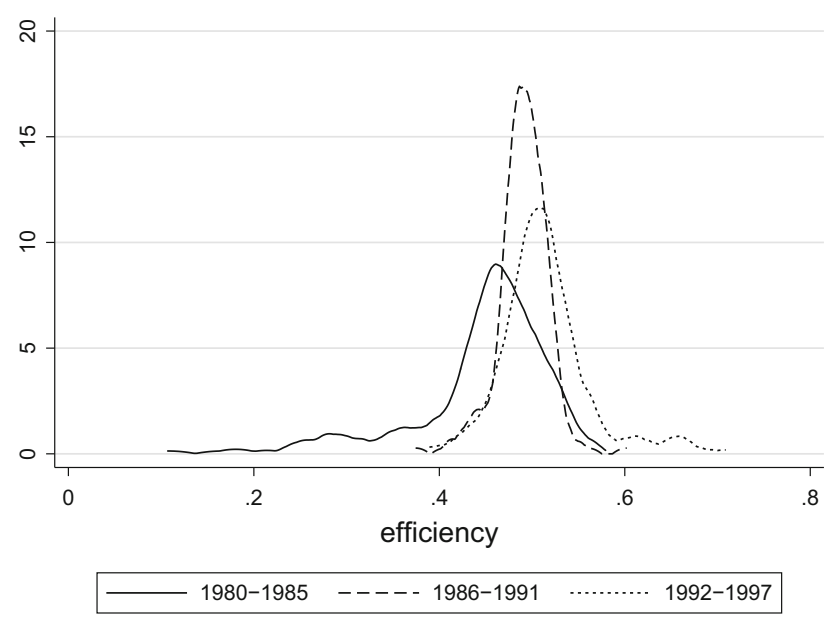

Kernel density plots for efficiency scores of high-technology group over time.

Fig. 3 Technical efficiency distribution in high-tech over time

(COK) and food products (FOD), respectively). Overall, the industries in the high technology regime are the fastest growers.

\subsection{Panel unit root and panel cointegration results}

In this subsection, we examine the co-movement of technical efficiency levels across countries and across regimes, respectively. We take annual averages of each technology regime in each country and study the properties of the resulting 24 series following a two-step procedure. The first step consists of examining whether each of the series (country- or regime-specific) are non-stationary by testing for unit roots. Evidence of panel unit roots (i.e., technical efficiency levels 'move') allows us to proceed to the second step, and test whether the series are cointegrated (i.e., whether the technical efficiency levels in different groups 'co-move'). As a further investigation, we examine the long-run linkages between the cointegrated series. To avoid biasing our results, we apply tests and estimators that account for cross-sectional dependence across the series.

\subsubsection{Are there spillovers across national borders?}

The first question we ask is whether there are any spillovers across countries. This is a question that a large strand of literature have concerned about. To answer such a question within our framework, we first need to test for panel unit roots in the efficiency series. Table 7a reports results from the Palm et al. (2008) test statistics and Table 8a from the Bai and Ng (2004) tests (see the "Appendix"). Overall, the panel-unit root tests provide strong support of unit root evidence, as the null hypothesis cannot be rejected at a $5 \%$ nominal size. In the presence of contradictory findings, for instance, for the case of Germany in Table 8a, we retain the results from the Palm et al. (2008) tests, as these tests explicitly consider the finite dimension of our panel whereas the Bai and $\mathrm{Ng}$ (2004) tests assume asymptotic distribution. We can therefore conclude that the efficiency series in each country are non-stationary and all of them must be included in the cointegration analysis, which is our next step.

In Table 3a, we report two cointegration tests (FDB1 and $F D B 2$ ), which are based on fast distribution bootstrap methods proposed by Fachin (2007) and control for crosssectional dependence. Both test statistics reject the null hypothesis of no cointegration at $10 \%$ and the hypothesis of one cointegrating vector is accepted. Support of cointegration of efficiency scores across borders implies that increased integration and competition in the EU have led to more efficient use of resources among industries in the countries of our sample. Thus efficiency levels have tracked one another over time as industries have attempted to follow each other's efficiency advances in order to remain competitive. Therefore, there is a long-run relationship in the technology transfer within the cointegrated set of the efficiency levels in the countries under investigation-a finding consistent with past related literature (Cornwell and Wächer 1999)—and potential convergence; in contrast, lack of cointegration could reflect a country's (industry's) inability to absorb the existing technology and potentially inability to converge with the rest of the set.

As a further exploration, we would like to investigate whether we can infer anything about the nature of long-run linkages among efficiency levels across countries. These linkages can be positive or negative, depending on the mechanisms at work. For instance, competition can force industries to increase their competitive capacity by reforming management styles and updating production technology, therefore enhancing the adoption of existing advanced technology. But it can also hamper the absorption of technology in case industries draw inputs from limited resource spaces and produce output to satisfy demand that typically is not completely inelastic. In the latter case, an industry may absorb technology at the expense of another industry (Aitken et al. 1997; Aitken and Harrison 1999; Girma 2005). As a result, either market-stealing (on the output side) or skill-stealing (on the input side) results in a negative long-run linkage among efficiency developments. Geographical proximity and intensity of trade also have a dual effect on spillovers (Audretsch and Feldman 2004). Industries in countries that trade more than others and/or share a common border, ceteris paribus, could experience stronger positive or negative long-run linkages in their technology absorption, either via higher technology flows, or via skill-stealing, assuming that labor is sufficiently mobile. 


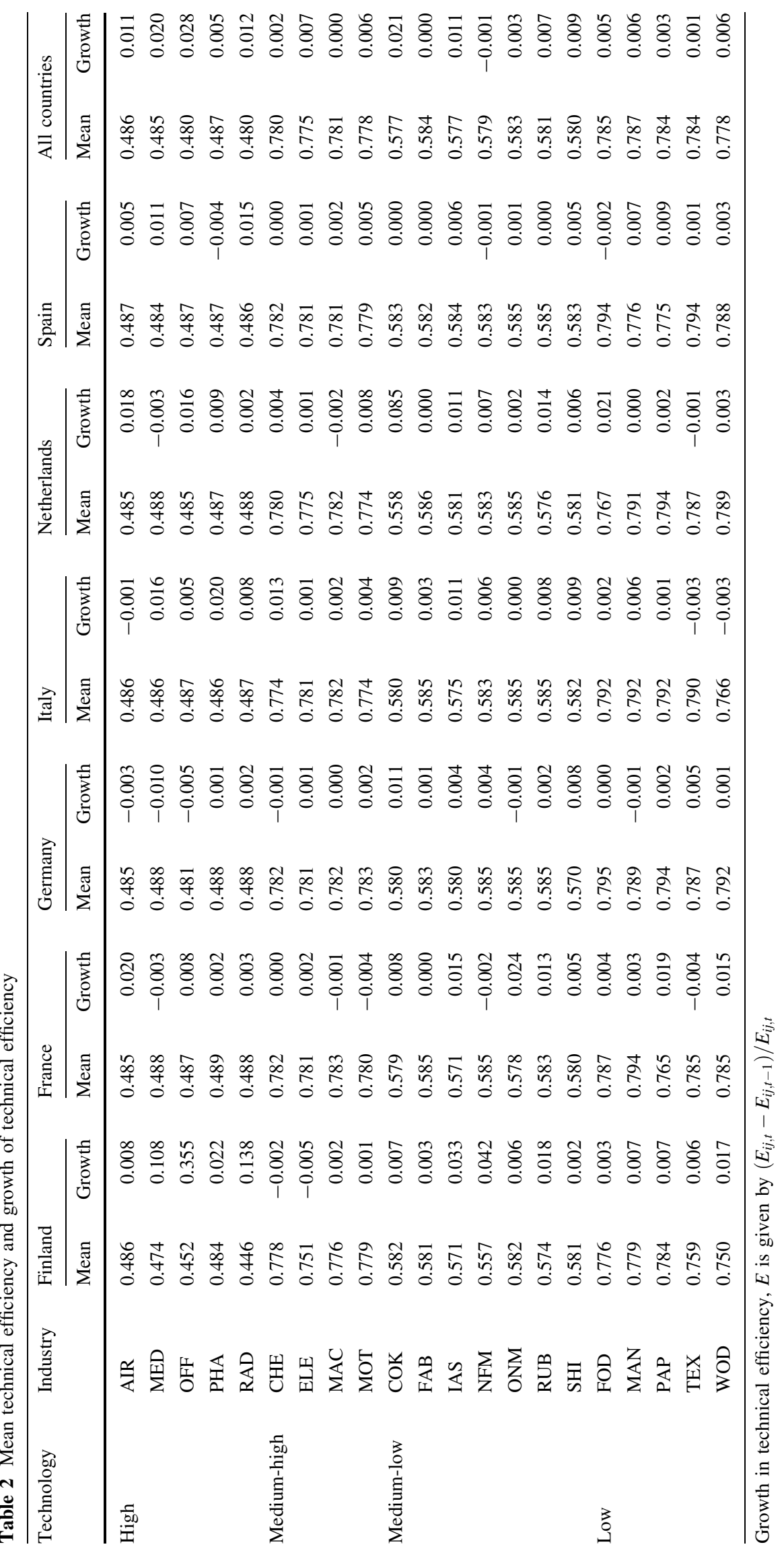


Table 3 Panel cointegration and estimation across countries

\begin{tabular}{|c|c|c|c|c|c|c|}
\hline \multicolumn{3}{|c|}{$F D B 1$} & $F D B 2$ & & & \\
\hline \multicolumn{7}{|c|}{ (a) Panel cointegration across countries } \\
\hline Mean & 7.50 & \multicolumn{2}{|c|}{7.40} & & & \\
\hline Median & 6.70 & \multicolumn{2}{|c|}{6.60} & & & \\
\hline Country & $\beta_{F I}$ & $\beta_{F R}$ & $\beta_{D E}$ & $\beta_{I T}$ & $\beta_{N L}$ & $\beta_{E S}$ \\
\hline \multicolumn{7}{|c|}{ (b) Panel estimation across countries } \\
\hline Finland & - & $\begin{array}{l}-0.700 \\
(0.170)\end{array}$ & $\begin{array}{l}0.680 \\
(0.139)\end{array}$ & $\begin{array}{l}-0.150 \\
(0.077)\end{array}$ & $\begin{array}{l}0.828 \\
(0.079)\end{array}$ & $\begin{array}{l}0.659 \\
(0.124)\end{array}$ \\
\hline France & $\begin{array}{l}-0.869 \\
(0.118)\end{array}$ & - & $\begin{array}{l}-0.371 \\
(0.142)\end{array}$ & $\begin{array}{l}-1.232 \\
(0.174)\end{array}$ & $\begin{array}{l}0.045 \\
(0.123)\end{array}$ & $\begin{array}{l}0.120 \\
(0.186)\end{array}$ \\
\hline Germany & $\begin{array}{l}-0.859 \\
(0.134)\end{array}$ & $\begin{array}{l}-0.831 \\
(0.216)\end{array}$ & - & $\begin{array}{l}-0.997 \\
(0.141)\end{array}$ & $\begin{array}{l}0.091 \\
(0.142)\end{array}$ & $\begin{array}{l}-0.065 \\
(0.194)\end{array}$ \\
\hline Italy & $\begin{array}{l}-0.596 \\
(0.095)\end{array}$ & $\begin{array}{l}-0.099 \\
(0.213)\end{array}$ & $\begin{array}{l}-0.068 \\
(0.142)\end{array}$ & - & $\begin{array}{l}-0.261 \\
(0.126)\end{array}$ & $\begin{array}{l}0.449 \\
(0.181)\end{array}$ \\
\hline Netherlands & $\begin{array}{l}-0.271 \\
(0.108)\end{array}$ & $\begin{array}{l}0.147 \\
(0.248)\end{array}$ & $\begin{array}{l}-0.075 \\
(0.176)\end{array}$ & $\begin{array}{l}-1.172 \\
(0.205)\end{array}$ & - & $\begin{array}{l}0.381 \\
(0.219)\end{array}$ \\
\hline Spain & $\begin{array}{l}-0.449 \\
(0.133)\end{array}$ & $\begin{array}{l}-0.156 \\
(0.269)\end{array}$ & $\begin{array}{l}-0.486 \\
(0.182)\end{array}$ & $\begin{array}{l}-0.807 \\
(0.182)\end{array}$ & $\begin{array}{l}0.066 \\
(0.153)\end{array}$ & - \\
\hline
\end{tabular}

FDB1 and FDB2 denote the two fast distribution bootstrapped tests proposed by Fachin (2007). FI, FR, DE, IT, NL and ES denote Finland, France, Germany, Italy, Netherlands and Spain, respectively. In all estimations, technical regime-specific fixed effects are introduced but not reported for sake of space. They are available from the authors upon request. Standard errors in (parentheses)

To assess the long-term linkages among efficiency levels in these countries, we use the BKN estimator for dynamic heterogeneous panels to estimate the long-run equations (6) for cross-border spillovers. However, we have to be careful in interpreting the results as they depend on normalization. Table $3 \mathrm{~b}$ reports the estimation results based on all different normalizations (i.e., every row of the table shows results based on the normalization of a certain country). ${ }^{26}$

As Table $3 b$ shows, we find evidence of negative longrun linkages among most of countries, most notably between neighboring countries such as France and Germany $(-0.371,-0.831)$ and France and Italy $(-1.232$, $-0.099)$, and Germany and Italy $(-0.997,-0.068)$. These negative linkages are not driven by technology spillovers, but rather by various forces such as market-stealing or skill-stealing that this study cannot precisely identify. For a small number of countries, for example France and the Netherlands $(0.045,0.147)$ and the Netherlands and Spain $(0.381,0.066)$, we find positive long-run linkages. The latter, however, are hardly ever significant.

\footnotetext{
${ }^{26}$ Since we use series for each of the four technology regimes in each country, we include regime-specific fixed effects (not reported here). Results from the other estimators are qualitatively similar and available upon request.
}

Lastly, for a number of pairs of countries we observe opposite signs for the long-run linkages. For example, whereas the coefficient for Italy in the panel estimation for Spain is 0.449 , the coefficient for Spain in the panel estimation for Italy is -0.807 . However, since most of the other results with opposite signs are not statistically significant and may depend on the normalization, we refrain from giving further economic meaning to these results.

To highlight the economic significance of these results, consider the following example: ceteris paribus, how much is the average change in output for industries in France that results from the sample period change in technical efficiency in, say, Finland? From Table 3b, we observe that for France, $\beta_{F I}$ is -0.869 . Using the period average efficiency scores for France and for Finland, we can calculate the elasticity, the effect of a percentage change in the average efficiency in Finland on the average efficiency in France, which is -0.85 . Given that Finnish industries on average increase their efficiency by $41.76 \%$ over the sample period, French industries are expected to decrease their average efficiency by $-35.65 \%(-0.85 \times 41.76)$, purely as a result of the negative spillovers from Finland. From the average value added level in 1980, we can calculate the average reduction in 1980 value added that would result from these negative spillovers, as the percentage drop in efficiency multiplied by the valued added in 1980 . The result turns out 
to be a reduction in value added of 2469.08 million euros, or $23.28 \%$ of the average 1980 output of French industries.

Although we find efficiency co-movements across countries in our sample, a justified concern is that aggregate (country-level) analysis of technology spillovers may mask important variations in efficiency patterns due to different technologies (or technological regimes) across industries (Scarpetta and Tressel 2002). A more appropriate way to investigate whether there are technology spillovers across the EU is to examine whether the efficiency scores of technologically neighboring or very far apart regimes are cointegrated (co-move) or not. Our next section proceeds with such an investigation.

\subsubsection{Are there spillovers across technology regimes?}

The second question we ask is, therefore, whether technology spills over across technology regimes. First, we test for panel unit roots in the efficiency series. Panel unit root tests for technical efficiency levels for each technology regime in our sample are reported in Tables $7 \mathrm{~b}$ and $8 \mathrm{~b}$ in the "Appendix". As the tests indicate, we find strong support for unit roots for all regimes. As before, in the presence of contradictory findings, for instance, for the case of medium-high technology regime in Table 8, we retain the results from the Palm et al. (2008) tests, as these tests explicitly consider the finite dimension of our panel whereas the Bai and $\mathrm{Ng}$ (2004) tests assume asymptotic distribution. Therefore, in each technology regime the efficiency series in the six countries are non-stationary.

Hence, we include all regimes in the panel cointegration tests reported in Table 4a. Both test statistics, FDB1 and $F D B 2$, are slightly above $10 \%$ indicating that test statistics is close to the nominal size. We thus take the decision to consider that the null hypothesis is rejected and thus to conclude in favor of the hypothesis of one cointegrating relationship.

So far, we have established that there is co-movement of the efficiency of industries with different technologies in the EU manufacturing sector. In order to investigate the type of long-run linkages implied between the different technology regimes, we proceed by estimating long-run cointegrating equation (7), using the same set of estimators described previously for our country analysis. Table $4 \mathrm{~b}$ reports the BKN estimator for dynamic heterogeous panels to estimate the long-run equations for cross-regime spillovers. ${ }^{27}$

From Table $4 \mathrm{~b}$ we can infer that technology spills over to neighboring technology regimes. We observe significant

\footnotetext{
27 Since we use series for each of the counties in our sample, we include country-specific fixed effects (not reported here). Results from the other estimators are qualitatively similar and available upon request.
}

Table 4 Panel cointegration and estimation across regimes

$$
\text { FDB1 FDB2 }
$$

(a) Panel cointegration across regimes

\begin{tabular}{lll} 
Mean & 12.20 & 12.10 \\
Median & 13.50 & 13.90 \\
\hline
\end{tabular}

\begin{tabular}{lllll}
\hline Regime & $\beta_{H}$ & $\beta_{M H}$ & $\beta_{M L}$ & $\beta_{L}$ \\
\hline (b) Panel estimation & across regimes & & \\
High & - & 0.376 & -0.128 & 0.135 \\
& & $(0.019)$ & $(0.098)$ & $(0.160)$ \\
Medium-high & -0.212 & - & 0.415 & 0.326 \\
& $(0.066)$ & & $(0.022)$ & $(0.145)$ \\
Medium-low & -0.133 & 0.082 & - & 0.411 \\
& $(0.074)$ & $(0.050)$ & & $(0.011)$ \\
Low & -0.001 & -0.114 & 0.142 & - \\
& $(0.118)$ & $(0.127)$ & $(0.100)$ & \\
\hline
\end{tabular}

FDB1 and FDB2 indicate the two fast bootstrapped tests proposed by Fachin (2007). In all panel estimations, country-specific fixed effect are introduced but not reported for sake of space. They are available from the authors upon request. Standard errors in (parentheses)

positive long-run linkages between industries in the medium-low and low $(0.418,0.142)$ as well as between medium-high and medium-low regimes $(0.415,0.082)$. In these types of regimes, technology tends to be rather stable which appears to have facilitated technology spillovers. In contrast, the evidence on the long-run relationship between the last pair of adjacent technology regimes, high and medium-high, is mixed $(0.391,-0.212){ }^{28}$

Mixed long-run linkages are also found for other regime combinations. For instance, there is a negative association between less technologically advanced regimes, namely the medium-high, medium-low and low regime and the most advanced regime, the high technology regime. A similar finding is also reported between the low and medium-high regimes. Since the estimator in these cases behaves differently, depending on the normalization, we are reluctant to provide further economic meaning to these results. We can only say that advanced technology industries tend to specialize in specific products/market niches, which reduces the scope for technological spillovers. ${ }^{29}$ The

\footnotetext{
${ }^{28}$ We would like to note here that the OECD classification used was based on data between 1991 and 1999 and the data used in this study started in 1980 . We also check whether our results stand when the 1991-1997 subsample is used. We also do the same for the crosscountry spillovers. Results are robust in both cases and available upon request.

${ }^{29}$ Scarpetta and Tressel (2002) provide evidence that the scope for technology spillovers in technologically advanced manufacturing industries is limited compared to less technologically advanced industries.
} 
dominance of one (or few) technologies gives scope for some positive spillovers from more advanced to less advanced technology regimes but not the other way around. Perhaps, in the long-run, there is some skill-stealing from the advanced technology regimes as skillful workforce in the less advanced technology regimes migrate to technology advanced regimes, in case of skill compatibility.

Positive linkages between adjacent technology regimes and weak (or even negative) linkages between technologically-distant regimes suggest that it is indeed easiest to appropriate technology that is closely related to your own (Scarpetta and Tressel 2002; Garcia Pascual and Westermann 2002). In his overview paper on R\&D spillovers, Griliches (1992) introduces a simple model where spillovers are decreasing in technological distance. He subsequently describes a number of studies that report the same evidence. Maurseth and Verspagen (2002), in their patent citation analysis for European regions also find that patent citations are industry specific and occur more often when the technological linkages between industries are stronger. Moretti (2004) studies human capital spillovers, and uses input-output flows, technological specialization, and patent citations to measure technological and economic distance. He finds that spillovers are decreasing in all three alternative measures.

Overall, we conclude that the greater the technology distance, the smaller the spillover effects are, and the learning effect takes places from more advanced to less advanced technology regimes. A possible channel for the latter is the forward and backward linkages between industries. $^{30}$

We can illustrate the economic significance of these results in the same manner as for the cross-border spillovers. For technology regime spillovers, consider the following question: ceteris paribus, how much is the average change in output for industries in the medium-high technology regime that results from the period change in technical efficiency in the high technology regime? From Table $4 \mathrm{~b}$, we observe that for medium-high technology industries, $\beta_{H}$ is -0.212 . Using the period average efficiency scores, we can calculate the elasticity, which is -0.13 . As high technology industries on average have increased their efficiency by $28.83 \%$ over the sample period, medium-high technology industries are expected to increase their average efficiency by $-3.80 \%(-0.13 \times$

\footnotetext{
${ }^{29}$ Scarpetta and Tressel (2002) provide evidence that the scope for technology spillovers in technologically advanced manufacturing industries is limited compared to less technologically advanced industries.

${ }^{30}$ Several studies, see for instance Javorcik (2004) and Liu (2008), have provided empirical evidence for technology spillovers across industries through the intermediate inputs they purchase from or sell to one another.
}

Table 5 Convergence across and within technology regimes in the manufacturing sector

\begin{tabular}{lcccc}
\hline Area & $\beta_{0}$ & $\beta_{1}$ & Elasticity & $R_{\text {adj }}^{2}$ \\
\hline (a) Convergence & across technology regimes & & \\
All countries & $0.124 * * *$ & $-0.190 * * *$ & -0.114 & 0.800 \\
Finland & $0.156 * * *$ & $-0.248 * * *$ & -0.125 & 0.702 \\
France & $0.076 * * *$ & $-0.118 * * *$ & -0.077 & 0.801 \\
Germany & $0.112 * * *$ & $-0.166 * * *$ & -0.111 & 0.942 \\
Italy & $0.076 * * *$ & $-0.116 * * *$ & -0.070 & 0.885 \\
Netherlands & $0.101 * * *$ & $-0.155 * * *$ & -0.089 & 0.892 \\
Spain & $0.096 * * *$ & $-0.146 * * *$ & -0.089 & 0.789 \\
(b) Convergence & within each technology regime & \\
High & $0.136 * * *$ & $-0.284 * * *$ & -0.114 & 0.766 \\
Medium-high & $0.078 * * *$ & $-0.099 * * *$ & -0.076 & 0.854 \\
Medium-low & $0.094 * * *$ & $-0.158 * * *$ & -0.085 & 0.937 \\
Low & $0.087 * * *$ & $-0.110 * * *$ & -0.083 & 0.909 \\
\hline Regressions in & &
\end{tabular}

Regressions in panel (a)for each country with technology regimespecific fixed effects; regressions in panel (b)for the EU area with country-specific fixed effects regressions for the EU area with country-technology regime-specific fixed effects; all regressions with robust standard errors; significance at the $10 / 5 / 1 \%$ level $(* / * * / * * *)$, semi-elasticities in the form of $\delta(y) / \delta(\ln x)$

28.83) as a result of the positive spillovers from the hightechnology industries. From the average value added level in 1980, we can again calculate the average reduction in 1980 value added that would result from these negative spillovers, which turns out to be 287.45 million euros, or $2.91 \%$ of the average 1980 output of medium-high technology industries.

\subsection{Convergence results}

We now turn to the analysis of convergence. We start by examining whether there is convergence in the manufacturing sector as a whole within each country and across all countries of our sample. We then go one step further, and test the convergence hypothesis within each technology regime.

\subsubsection{Is there convergence across national borders?}

We start by estimating equation (8) for the manufacturing sector in each country and across countries. Table 5a reports the convergence coefficient, $\beta_{1}$, for each country and all countries. The results also provide evidence of convergence within each of the countries. However, the evidence appears to be the strongest for Finland and Germany. The Netherlands and Spain follow at a modest distance, and convergence is the lowest in France and Spain.

It is interesting to relate these findings with the past literature. Our results run counter to the lack of (or very 
little) evidence of convergence documented in the literature for the manufacturing sector (Hansson and Henrekson 1997; Bernard and Jones 1996a, b). This is mainly due to the fact that the majority of the past studies test for convergence in total factor productivity (TFP) as a proxy of the technology level. TFP is measured as a growth accounting (Solow-) residual under rather limiting assumptions about the existing technology (represented by a Cobb-Douglas production function and Hicks neutral technology change) and the behavior of economic units (optimizing behavior with no room for inefficiency).

To benefit from spillovers, industries have to incur (costly) input changes. In contrast, we are line with Arcelus and Arocena (2000), who also perform a frontier analysis and focus on efficiency to measure technology spillovers. Efficiency changes do not require input changes and therefore they can be considered a more 'pure' measure of technology adoption. Indeed, Arcelus and Arocena (2000) find a high degree of catching-up among 14 OECD countries over 1970-1990 in the manufacturing sector.

\subsubsection{Is there convergence across technology regimes?}

Although convergence in the manufacturing comes out particularly strong in each and every country and across countries in our sample, a justified concern is that aggregate (manufacturing sector) analysis of technology spillovers and productivity can mask important variations in convergence patterns due to different technology across industries (Garcia Pascual and Westermann 2002; Scarpetta and Tressel 2002; Boussemart et al. 2006).

This concern, that heterogeneity in existing technologies might be an issue in efficiency performance and in studying the convergence hypothesis in the manufacturing, has been validated in previous sections of our paper. In Sect. 3.1, we described the mean and growth of efficiency in four technology regimes (groups) across countries in our sample. From Fig. 2, we observed that the average efficiency was relatively low for industries in high and medium-low technology regimes. In addition, the spread of efficiency was relatively high for these technology regimes. Table 2 then showed that almost all industries in all technology regimes and countries exhibited positive growth of efficiency. In sum, our frontier results suggest that there is ample room for (differences in) convergence, in particular among industries located in high and medium-low technology regimes.

Our next step, therefore, involves investigation of convergence across industries with a similar technology. Table $5 \mathrm{~b}$ contains the results from estimating equation (8), per technology regime and across countries. Negative and significant values for $\beta_{1}$ indicate that there is convergence in all technology regimes. Indeed, the high technology regime experiences the strongest convergence. In the medium-low technology regime, convergence is also strong, as in the low technology regime, while the mediumhigh technology regime, on average, experiences the lowest level of convergence.

In the lower technology regimes (low and medium-low), the fact that the existing technology tends to be rather stable appears to have facilitated technology spillovers and convergence. This finding is in line with the literature (Scarpetta and Tressel 2002). In contrast, our finding of strong convergence in the high technology regime appears at first to be surprising, since patent laws, product and market differentiation can reduce the scope for technology spillovers. Our results suggest the presence of some dominant technologies in the high technology regime industries could be responsible for the evidence of convergence. Perhaps, persisting institutional differences, in particular related to product and labor market regulations, affect technology adaptation, particularly for the most technologically advanced and innovative industries. ${ }^{31}$

Overall, our findings yield (1) strong evidence of convergence across countries is documented when technical efficiency is used to study the convergence hypothesis in the manufacturing sector; and (2) even stronger evidence of convergence across technology regimes, when we disaggregate the manufacturing sector into different sub-sectors and control for differences in technology. However, the strength of the convergence varies, depending on the regime.

\section{Conclusion}

It has been long recognized that international technology transfer is an important source of growth and that the progress of nations may be determined in part by its extent. This paper investigates whether technology spills over across national borders and technology regimes. We

\footnotetext{
31 Differences in the stringency of regulatory settings across countries could have an impact on technology adaptation and convergence. Product and labor market regulations, for instance, can reduce incentives to invent and adopt better technology and catch up with the technological leader. Specifically, strict (anti-competitive) product market regulation is found to hinder the adoption of existing technologies, possibly because it reduces competitive pressures or technology spillovers (Nicoletti et al. 2001; Bassanini and Ernst 2002). There is also evidence that strict employment protection legislation results in high hiring and firing costs that impede productivity improvements, especially when wages and/or internal training do not offset these higher costs, thereby resulting in suboptimal adjustments of the workforce to technology changes and less incentives to innovate (Scarpetta and Tressel 2002).
} 
advocate a modeling strategy where changes in technical efficiency capture technology spillovers as industries absorb and implement the best-practice (frontier) technology. By estimating a frontier model of production we are able to measure the technical efficiency with which industries employ their production technology.

We contribute to the literature by controlling for technological heterogeneity and for cross-sectional dependence in the data. More specifically, we take into account the appropriateness of the technology that industries use and benchmark each industry against other industries within the same technology regime. Hence, in our analysis, a (positive) technology spillover (i.e., an increase in efficiency) is indeed an improvement in the use of the existing technology, rather than a change in the latter. Also, we control for the fact that countries and technology regimes are not necessarily cross-sectionally independent and use recently developed dynamic panel-based techniques to determine whether efficiency series move together in the long run (cointegrate) and/or move closer together over time (converge).

We use a panel of 21 manufacturing industries in four technology regimes and six EU countries over the period 1980-1997, and-after taking country- and regime-specific annual averages - study the properties of the resulting 24 technical efficiency series. We, first, ask whether technology spills over across borders, and find that technical efficiency series are cointegrated with each other across all countries. A further analysis of the long-run linkages reveals that crosscountry technology spillovers are predominantly negative, indicating possible market- and/or skill-stealing. Next, we ask whether technology spills over across regimes, and find that technical efficiency series are cointegrated with each other across all technology regimes. Among technology regimes, long-run linkages are predominantly positive, emphasizing therefore the importance of technological rather than geographical proximity for technology spillovers.

We also find fairly strong evidence of convergence, both across countries and technology regimes. Over time, the technical efficiency series of industries in the manufacturing sector have moved closer together. However, the extent to which this has happened differs. In the northern countries (Finland, Germany), convergence is the strongest. In particular, industries in the high technology regime emerge as the drivers behind the convergence of efficiency.

Acknowledgments We thank Rob Alessie, Rabah Arezki, Christian Gengenbach, William Greene, Stephano Fachin, Wolfgang Keller, Barbara Meller, Mark Sanders, Spiro Stefanou, and Mike Tsionas for valuable comments on previous drafts of this paper. The usual disclaimer applies.

Open Access This article is distributed under the terms of the Creative Commons Attribution 4.0 International License (http://crea tivecommons.org/licenses/by/4.0/), which permits unrestricted use, distribution, and reproduction in any medium, provided you give appropriate credit to the original author(s) and the source, provide a link to the Creative Commons license, and indicate if changes were made.

\section{Appendix}

\section{Variables and sources}

Value-Added (Y): gross value-added expressed in 1995 constant prices (euros). Gross value-added was deflated by implicit value-added deflators to yield deflated gross valueadded expressed in 1995 constant prices (euros). We follow the OECD (2002) practice for the construction of the implicit value-added deflators. Data on gross value-added are retrieved from the OECD (2002) STAN Structural Analysis Database.

Physical capital $(K)$ : gross capital stock expressed in 1995 constant prices (euros). Following common practice in the literature (e.g. Hall and Jones, 1999), we employ the perpetual inventory method to construct a proxy for capital stock, using data on gross fixed capital formation (GFCF). The initial value for the 1980 capital stock is specified as $K_{1980}=G F C F_{1980} /(g+\delta)$, where $g$ is the average geometric growth rate of the gross fixed capital formation (constant prices) series from 1970 to 1980 and $\delta$ is the depreciation rate. Instead of assuming a constant depreciation rate, we use the average service life (ASL) of capital per industry (OECD 1993). Each industry's capital stock is constructed as capital stock minus depreciated capital stock plus gross fixed capital formation $\left(K_{t}=(1-\delta) \times K_{t-1}+\right.$ $\left.G F C F_{t}\right)$. Data on gross fixed capital formation are retrieved from the OECD (2002) STAN Structural Analysis Database.

Labor $(L)$ : annual total hours worked in an industry (in thousands). Data are retrieved from the Groningen Growth and Development Centre (GGDC 2006) 60-Industry Database (Table 6).

\section{Panel unit root tests}

See Tables 7 and 8 . 
Table 6 Manufacturing industries
Table 7 Palm et al. (2008) bootstrap tests

\begin{tabular}{lll}
\hline Industry & Abbreviation & ISIC code (Rev. 3) \\
\hline Coke, refined petroleum products and nuclear fuel & COK & 23 \\
Textiles, textiles products, leather and footwear & TEX & $17-19$ \\
Building and repairing ships and boats & SHI & 351 \\
Food products, beverages and tobacco & FOD & $15-16$ \\
Non-ferrous Metals & NFM & $272+2732$ \\
Other non-metallic mineral products & ONM & 26 \\
Wood, and products of wood and cork & WOD & 20 \\
Iron and steel & IAS & $27+2731$ \\
Machinery and equipment, n.e.c. & MAC & $36+37$ \\
Chemicals (excl. pharmaceuticals) & CHE & 24 less 2423 \\
Pulp, paper, paper products, printing and publishing & PAP & $21-22$ \\
Manufacturing n.e.c.; recycling & MAN & 29 \\
Motor vehicles, trailers and semi-trailers & MOT & 34 \\
Fabricated Metal products (excl. mach. and equip.) & FAB & 28 \\
Aircraft + spacecraft & AIR & 353 \\
Rubber and plastics products & RUB & 25 \\
Pharmaceuticals & PHA & 2423 \\
Electrical machinery and apparatus & ELE & 31 \\
Medical, precision and optical instruments & MED & 33 \\
Radio, television and communication equipment & RAD & 32 \\
Office, accounting and computing machinery & OFF & 30 \\
\hline
\end{tabular}

\begin{tabular}{lccc}
\hline & Test & $t$ value & Root \\
\hline (a) Panel unit root tests across countries & & & \\
Finland & & & \\
Levin-Lin-Chu (LLC) & -0.508 & -2.01 & $\mathrm{I}(1)$ \\
Im-Pesaran-Shin (IPS) & 0.141 & -13.469 & $\mathrm{I}(1)$ \\
France & & & \\
Levin-Lin-Chu (LLC) & 0.064 & -2.593 & $\mathrm{I}(1)$ \\
Im-Pesaran-Shin (IPS) & 2.221 & -15.868 & $\mathrm{I}(1)$ \\
Germany & & & \\
Levin-Lin-Chu (LLC) & -0.528 & -0.827 & $\mathrm{I}(1)$ \\
Im-Pesaran-Shin (IPS) & -1.354 & -15.329 & $\mathrm{I}(1)$ \\
Italy & & -1.035 & $\mathrm{I}(1)$ \\
Levin-Lin-Chu (LLC) & -0.208 & -13.116 & $\mathrm{I}(1)$ \\
Im-Pesaran-Shin (IPS) & -0.378 & & \\
Netherlands & & -1.812 & $\mathrm{I}(1)$ \\
Levin-Lin-Chu (LLC) & -0.073 & -13.118 & $\mathrm{I}(1)$ \\
Im-Pesaran-Shin (IPS) & -4.729 & -11.535 \\
Spain & & -16.611 & $\mathrm{I}(1)$ \\
Levin-Lin-Chu (LLC) & 1.028 & & $\mathrm{I}(1)$ \\
Im-Pesaran-Shin (IPS) & -0.870 & & \\
(b) Panel unit root tests across regimes & & & \\
High & & & \\
Levin-Lin-Chu (LLC) & 0.063 & & \\
Im-Pesaran-Shin (IPS) & & & \\
Medium-high & 0.4129 & \\
Levin-Lin-Chu (LLC) & & & \\
\hline
\end{tabular}


Table 7 continued

\begin{tabular}{llcc}
\hline & Test & $t$ value & Root \\
\hline Im-Pesaran-Shin (IPS) & 1.295 & -11.566 & $\mathrm{I}(1)$ \\
Medium-low & & & \\
Levin-Lin-Chu (LLC) & -0.298 & -0.898 & $\mathrm{I}(1)$ \\
Im-Pesaran-Shin (IPS) & -1.1602 & -15.424 & $\mathrm{I}(1)$ \\
Low & & & \\
Levin-Lin-Chu (LLC) & -0.517 & -1.222 & $\mathrm{I}(1)$ \\
Im-Pesaran-Shin (IPS) & -6.955 & -12.160 & $\mathrm{I}(1)$ \\
\hline
\end{tabular}

Panel unit root tests include an intercept and a trend. The number of lags is two. For LLC, IPS, the null hypothesis is that all time series are I(1) and the length of the kernel window is fixed to 3.000. Similar results are obtained with other window sizes and are available from authors upon request. Tests for LLC and IPS are left-sided tests

Table 8 Bai and $\mathrm{Ng}(2004)$ two common factors test

\begin{tabular}{lrr}
\hline Country & $P$ & Root \\
\hline (a) Panel unit root tests across countries & \\
Finland & -2.000 & $\mathrm{I}(1)$ \\
France & -2.020 & $\mathrm{I}(1)$ \\
Germany & -1.361 & $\mathrm{I}(0)$ \\
Italy & -2.003 & $\mathrm{I}(1)$ \\
Netherlands & -5.516 & $\mathrm{I}(1)$ \\
Spain & -1.797 & $\mathrm{I}(1)$ \\
(b) Panel unit root tests across & regimes & \\
Regimes & & \\
High & -2.346 & $\mathrm{I}(1)$ \\
Medium-high & -0.510 & $\mathrm{I}(0)$ \\
Medium-low & -1.652 & $\mathrm{I}(1)$ \\
Low & -2.449 & $\mathrm{I}(1)$ \\
\hline
\end{tabular}

$P$ reports the statistics of the Bai and $\mathrm{Ng}$ (2004) panel unit root test. Asymptotic critical value at a $5 \%$ level is 1.645 . Rejection of the null hypothesis, $\mathrm{I}(0)$, when $P$ is greater than the critical value

\section{References}

Abramovitz M (1986) Catching up, forging ahead, and falling behind. J Econ Hist 46(2):385-406

Acemoglu D, Zilibotti F (2001) Productivity differences. Q J Econ 116(2):563-606

Aitken BJ, Harrison AE (1999) Do domestic firms benefit from direct foreign investment? Evidence from Venezuela. Am Econ Rev 89(3):605-618

Aitken B, Hanson GH, Harrison AE (1997) Spillovers, foreign investment, and export behavior. J Int Econ 43(1-2):103-132

Arcelus FJ, Arocena P (2000) Convergence and productive efficiency in fourteen OECD countries: a non-parametric frontier approach. Int J Prod Econ 66(2):105-117

Audretsch BD, Feldman MP (2004) Knowledge spillovers and the geography of innovation. In: Handbook of regional and urban economics, vol 4, Ch 61. Elsevier, The Netherlands, 2713-2739
Bai J, Ng S (2004) A panic attack on unit roots and cointegration. Econometrica 72(4):1127-1177

Bai J, Kao C, Ng S (2009) Panel cointegration with global stochastic trends. J Econom 149(1):82-99

Baltagi BH, Griffin JM (1988) A general index of technical change. J Polit Econ 96(1):20-41

Banerjee A, Marcellino M, Osbat C (2000) Some cautions on the use of panel methods for integrated series of macro-economic data. Working Papers 170, IGIER (Innocenzo Gasparini Institute for Economic Research), Bocconi University

Barro RJ (1991) Economic growth in a cross section of countries. Q J Econ 106(2):407-443

Barro RJ (1997) Determinants of economic growth: a cross-country empirical study. MIT Press, Cambridge

Barros CP, Dieke PUC (2008) Measuring the economic efficiency of airports: a Simar-Wilson methodology analysis. Transp Res Part E 44:1039-1051

Bassanini A, Ernst E (2002) Labor market institutions, product market regulation, and innovation: cross country evidence. OECD Economics Department Working Papers No 316, Paris

Basu S, Weil D (1998) Appropriate technology and growth. Q J Econ 113(4):1025-1054

Battese GE, Coelli JT (1995) A model for technical inefficiency effects in a stochastic frontier production function for panel data. Empir Econ 20(2):325-332

Baumol W (1986) Productivity growth, convergence, and welfare: what the long-run data show. Am Econ Rev 76(5):1072-1085

Bernard AB, Jones CI (1996a) Comparing apples to oranges: productivity convergence and measurement across industries and countries. Am Econ Rev 86(5):1216-1238

Bernard AB, Jones CI (1996b) Productivity across industries and countries: time series theory and evidence. Rev Econ Stat 78(1):135-146

Bos JWB, Economidou C, Koetter M (2010a) Technology clubs, R\&D and growth patterns: evidence from EU manufacturing. Eur Econ Rev 54(1):60-79

Bos JWB, Economidou C, Koetter M, Kolari JW (2010b) Do all countries grow alike? J Dev Econ 91(1):113-127

Boussemart J-P, Briec W, Cadoret I, Tavera C (2006) A reexamination of the technological catching-up hypothesis across OECD industries. Econ Model 23(6):967-977

Cameron G, Proudman J, Redding S (2005) Technological convergence, $R \& D$, trade and productivity growth. Eur Econ Rev 49(3):775-809

Chen B, McCoskey S, Kao C (1999) Estimation and inference of a cointegrated regression in panel data: a Monte Carlo study. Am J Math Manag Sci 19(1-2):75-114 
Coe DT, Helpman E (1995) International R\&D spillovers. Eur Econ Rev 39(5):859-887

Coe TD, Helpman E, Hoffmaister AW (2009) International R\&D spillovers and institutions. Eur Econ Rev 53(7):723-741

Cohen WM, Levinthal DA (1989) Innovation and learning: the two faces of R\&D. Econ J 99(397):569-596

Cornwell CM, Wächer J-U (1999) Productivity convergence and economic growth: a frontier production function approach. Center for European Integration Studies, Working Paper B6/ 1999

Davidson R, MacKinnon JG (2000) Improving the reliability of bootstrap tests. Working Papers 995, Queen's University, Department of Economics

Diewert WE (1976) Exact and superlative index numbers. J Econom 4(2):115-145

Dreger C, Reimers H-E (2005) Health care expenditures in oecd countries: a panel unit root and cointegration analysis. IZA Discussion Papers 1469, Institute for the Study of Labor (IZA)

Fachin S (2007) Long-run trends in internal migrations in Italy: a study in panel cointegration with dependent units. J Appl Econom 22(2):401-428

Fagerberg J, Verspagen B (1999) Productivity, R\&D spillovers and trade. Centre for Technology, Innovation and Culture, University of Oslo, Working Papers 3

Falvey R, Foster N, Greenaway D (2004) Imports, exports, knowledge spillovers and growth. Econ Lett 85(2):209-213

Frantzen D (2000) R\&D, human capital and international technology spillovers: a cross-country analysis. Scand Audiologyd J Econ 102(1):57-75

Frantzen D (2002) Intersectoral and international R\&D knowledge spillovers and total factor productivity. Scott J Polit Econ 49(3):280-303

Garcia Pascual A, Westermann F (2002) Productivity convergence in European manufacturing. Rev Int Econ 10(2):313-323

Gengenbach C, Franz CP, Urbain J-P (2010) Panel unit root tests in the presence of cross-sectional dependencies: comparison and implications for modelling. Econom Rev 29(2):111-145

GGDC (2006) Groningen Growth and Development Centre 60-industry database. GGDC, Groningen

Girma S (2005) Absorptive capacity and productivity spillovers from FDI: a threshold regression analysis. Oxf Bull Econ Stat 67(3):281-306

Greene W (2005) Reconsidering heterogeneity in panel data estimators of the stochastic frontier model. J Econom 126(2):269-303

Griffith R, Redding S, van Reenen J (2004) Mapping the two faces of $\mathrm{R} \& \mathrm{D}$ : productivity growth in a panel of OECD industries. Rev Econ Stat 86(4):883-895

Griliches Z (1992) The search for R\&D spillovers. Scand J Econ 94:S29-47

Groen JJ, Kleinbergen F (2003) Likelihood-based cointegration analysis in panels of vector error correction models. J Bus Econ Stat 21(2):295-318

Grossman G, Helpman E (1991) Endogenous product cycles. Econ J 101(408):1214-1229

Hansson P, Henrekson M (1997) Catching up, social capability, government size and economic growth. In: Bergström V (ed) Government and growth. Clarendon Press, Oxford, pp 61-126

Im KS, Pesaran HM, Shin Y (1997) Testing for unit roots in heterogeneous panels. Mimeo

Im KS, Pesaran HM, Shin Y (2003) Testing for unit roots in heterogeneous panels. J Econom 115(1):53-74

Javorcik BS (2004) Does foreign direct investment increase the productivity of domestic firms? Am Econ Rev 94(3):605627

Jones CI (2005) The shape of production functions and the direction of technical change. Q J Econ 120(2):517-549
Kao C, Chiang M-H (2000) On the estimation and inference of a cointegrated regression in panel data. Adv Econom 15:197-202

Kao C, Chiang M-H, Chen B (1999) International R\&D spillovers revisited: an application of estimation and inference in panel cointegration. Oxf Bull Econ Stat 61(S1):691-709

Keller W (1998) Are international R\&D spillovers trade-related? Analyzing spillovers among randomly matched trade partners. Eur Econ Rev 42(8):1469-1481

Keller W (2002) Trade and transmission of technology. J Econ Growth 7(1):5-24

Kneller R, Stevens P (2006) Frontier technology and absorptive capacity: evidence from OECD manufacturing industries. Oxf Bull Econ Stat 68(1):1-21

Koop G (2001) Cross-sectoral patterns of efficiency and technical change in manufacturing. Int Econ Rev 42(1):73-103

Koopmans TC (1951) An analysis of production as an efficient combination of activities. In: Koopmans TC (ed) Activity analysis of production as an efficient combination of activities, vol 13. Wiley, New York, pp 33-97 Cowles Commission for Research in Economics Monograph

Levin A, Lin C-F (1992) Unit root tests in panel data: new results. University of California, San Diego Working Paper 93-56

Levin A, Lin C-F (1993) Unit root tests in panel data: asymptotic and finite sample properties. University of California, San Diego Working Paper 92-23

Levin A, Lin C-F, Chu C-SJ (2002) Unit root tests in panel data: asymptotic and finite sample properties. J Econom 108(1):1-24

Lichtenberg RF, Potterie BVPDL (1998) International R\&D spillovers: a re-examination. Eur Econ Rev 42(8):1483-1491

Lichtenberg RF, Potterie BVPDL (2001) Does foreign direct investment transfer technology across borders? Rev Econ Stat 83(3):490-497

Liu Z (2008) Foreign direct investment and technology spillovers: theory and evidence. J Dev Econ 85(1-2):176-193

Luintel BK, Khan M (2004) Are international R\&D spillovers costly for the united states? Rev Econ Stat 86(4):896-910

Maurseth PB, Verspagen B (2002) Knowledge spillovers in europe: a patent citations analysis. Scand J Econ 104(4):531-545

Mohnen P (1996) Information technology, productivity and economic growth: international evidence and implications for economic development. In: Pohjola M (ed) International R\&D spillovers and economic growth. Oxford University Press, Oxford, pp 50-71

Moretti E (2004) Workers' education, spillovers, and productivity: evidence from plant-level production functions. Am Econ Rev 94(3):656-690

Nicoletti G, Bassanini A, Ernst E, Jean S, Santiago P, Swaim P (2001) Product and labour market interactions in oecd countries. OECD Economics Department Working Paper 312

OECD (1993) Methods used by OECD countries to measure stocks of fixed capital. OECD, Paris

OECD (2002) OECD structural analysis database (STAN). OECD, Paris

OECD (2005) OECD science, technology and industry scoreboard. OECD, Paris

Orea L, Kumbhakar SC (2004) Efficiency measurement using a latent class stochastic frontier model. Empir Econ 29(1):169-183

Palm FC, Smeekes S, Urbain J-P (2008) Bootstrap unit-root tests: comparison and extensions. J Time Ser Anal 29(2):371-401

Park J (2004) Internatinal and intersectoral R\&D spillovers in the OECD and East Asian economies. Econ Inquiry 42(4):739-757

Pedroni P (1999) Critical values for cointegration tests in heterogeneous panels with multiple regressors. Oxf Bull Econ Stat 61:653-670 (Special Issue)

Pedroni P (2001) Purchasing power parity tests in cointegrated panels. Rev Econ Stat 83(4):727-731 
Pesaran MH (2004) General diagnostic tests for cross section dependence in panels. University of Cambridge, Cambridge Cambridge working papers in economics

Phillips CP, Sul D (2003) Dynamic panel estimation and homogeneity testing under cross section dependence. Econom J 6(1):217-259

Rivera-Batiz LA, Romer PM (1991) Economic integration and economic growth. Q J Econ 106(2):531-555

Romer PM (1990) Endogenous technological change. J Polit Econ 98(5):71-102

Scarpetta S, Tressel T (2002) Productivity and convergence in a panel of OECD industries: Do regulations and institutions matter? OECD Economics Department Working Papers No. 342

Semenick Alam IM, Sickles RC (2000) Time series analysis of deregulatory dynamics and technical efficiency: the case of the U.S. airline industry. Int Econ Rev 41(1):203-218
Simar L, Wilson PW (2007) Estimation and inference in two-stage, semi-parametric models of production processes. J Econom 136(1):31-64

Stock JH (1987) Asymptotic properties of least squares estimations of cointegrating vectors. Econometrica 55(5):1035-1056

Tsionas E, Christopoulos D (2001) Efficiency measurement with nonstationary variables: an application of panel cointegration techniques. Econ Bull 3:1-7

Van Biesebroeck J (2007) Robustness of productivity estimates. J Ind Econ LV 3(3):529-569 